\title{
Characterisation of the Abnormal Pancreatic D and A Cell Function in Streptozotocin Diabetic Dogs: Studies with D-Glyceraldehyde, Dihydroxyacetone, D-Mannoheptulose, D-Glucose, and L-Arginine
}

\author{
K. Hermansen \\ Second University Clinic of Internal Medicine, Kommunehospitalet, Aarhus, Denmark
}

Summary. Pancreatic D and A cell function is deranged in streptozotocin diabetes. To investigate this, the effect of D-glyceraldehyde, dihydroxyacetone, Dmannoheptulose and glucose variations during arginine stimulation on the release of somatostatin and glucagon from the isolated pancreas of normal and streptozotocin diabetic dogs was studied. Concentrations of the trioses, D-glyceraldehyde (1.25 and $2.5 \mathrm{mmol} / \mathrm{l})$ and dihydroxyacetone $(11 \mathrm{mmol} / \mathrm{l})$, which normally stimulate D cells, did not influence the release of somatostatin in the diabetic dog. However, the higher concentration of D-glyceraldehyde $(5 \mathrm{mmol} / \mathrm{l})$ suppressed D cell secretion in the diabetic animals at 0 and $8.3 \mathrm{mmol} / 1$ glucose. A cell secretion was significantly suppressed at the higher glucose level in response to both 2.5 and $5 \mathrm{mmol} / 1$ of the triose. This inhibition may be explained by a non-specific effect induced by the high dose of this triose. The addition of $5 \mathrm{mmol} / \mathrm{l}$ mannoheptulose, which normally reduces glucose-induced somatostatin secretion and stimulates glucagon release, did not affect hormone secretion. In both the diabetic and the normal animals, arginine $(5 \mathrm{mmol} / \mathrm{l})$ stimulated somatostatin and glucagon secretion. Although arginine was able to stimulate $\mathrm{D}$ and $\mathrm{A}$ cell secretion in the diabetic dogs, it was however unable to restore the response to changes in glucose concentration between 1.4 and $8.3 \mathrm{mmol} / 1$ to normal. These results demonstrate that the abnormal pancreatic $D$ and $A$ cell function in streptozotocin diabetes is characterised by an impaired response to glucose and certain glucose metabolites and probably results from a specific defect in glucose recognition.

Key words: Pancreas, diabetes, somatostatin, glucagon, insulin, D-glyceraldehyde, dihydroxyacetone, mannoheptulose, glucose, arginine, isolated perfused pancreas.
Deranged function has recently been demonstrated in the pancreatic $D$ cells in experimental diabetes [1]. No alteration in the release of somatostatin from the pancreas of streptozotocin diabetic dogs was found in response to changes in the concentration of glucose during its perfusion [1], whereas normally they are accompanied by a swift change in D cell secretion [2-5]. In contrast, various other somatostatin secretagogues, e. g. arginine [1, 6], calcium [1], isoprenaline [1], and glucagon [7] were all able to stimulate somatostatin secretion from the diabetic pancreas. These results therefore suggest a selective insensitivity of the diabetic $D$ cell to glucose. Whether this insensitivity applies only to the intact glucose molecule or also to glucose metabolites is unknown. To further elucidate the nature of the $\mathrm{D}$ cell abnormality in experimental diabetes, somatostatin responses were therefore studied in the isolated perfused pancreas of streptozotocin diabetic dogs to two glucose metabolites, glyceraldehyde and dihydroxyacetone, which stimulate D cell secretion [8] and to mannoheptulose, which inhibits glucose mediated D cell secretion $[2,8]$ in the normal dog. In addition, the ability of arginine to restore the pancreatic D cell response to glucose to normal in diabetic dogs was investigated.

\section{Material and Methods}

Animals and Perfusion System: Mongrel dogs, weighing 16-27 kg were used in the study. In 11 dogs diabetes was induced with streptozotocin ( $50 \mathrm{mg} / \mathrm{kg}$ IV). Blood samples were obtained from the diabetic animals just before the streptozotocin infusion, after an overnight fast. The diabetic dogs were then given a normal diet and daily IV saline treatment $(500-1000 \mathrm{ml})$ for periods of $3-5$ days before the operation. Insulin was not administered. After an overnight fast and just before anaesthesia, further blood samples were collected from all the diabetic animals.

Venous blood from a foreleg was collected into tubes containing $10,000 \mathrm{KIU} / \mathrm{ml}$ Trasylol (FBA Pharmaceuticals, New York, USA) and $3 \mathrm{mg} / \mathrm{ml}$ EDTA ( $\mathrm{pH}=8$ ) which were kept on ice for up to $20 \mathrm{~min}$. The plasma was separated by centrifugation and stored
} 
at $-18^{\circ} \mathrm{C}$ until the assay of glucagon and insulin levels. Blood for glucose determination was collected in tubes containing sodium fluoride and stored at $-18^{\circ} \mathrm{C}$ until analysis.

All the dogs were subjected to the same procedure after the overnight fast. The technique for isolation of the pancreas and the perfusion system have previously been described in detail [9]. In brief, the preparation consisted of the pancreas and the proximal $10 \mathrm{~cm}$ of the attached duodenum. A non-recirculating medium consisting of a Krebs-Ringer bicarbonate buffer containing $40 \mathrm{~g} / 1$ dextran (mol. wt. 75,000), $2 \mathrm{~g} / 1$ bovine albumin and glutamate, $\mathrm{fu}-$ marate, and pyruvate (each $5 \mathrm{mmol} / \mathrm{l}$ ) was pumped through the splenic and coeliac arteries. The total portal effluent was collected every minute. Unless otherwise indicated glucose was not added to the medium.

The perfusate was oxygenated by a rotating roller screen in an atmosphere of $94.4 \% \mathrm{O}_{2}$ and $5.6 \% \mathrm{CO}_{2}$. The perfusion fluid was kept at $37{ }^{\circ} \mathrm{C}$ and a constant $\mathrm{pH}$ of 7.4 , its perfusion pressure being $30-40 \mathrm{~mm} \mathrm{Hg}$ and its flow rate $20 \mathrm{ml} / \mathrm{min}$.

Experimental Protocol: Samples were taken every minute from the efflux. To prevent the possible degradation of somatostatin and insulin in the efflux, EDTA $3 \mathrm{mg} / \mathrm{ml}$ was added to the collecting tubes. The samples were immediately stored at $-18^{\circ} \mathrm{C}$ until analysis.

Each pancreas was perfused for an equilibration period of 20-30 min, then the test substances were infused for 10-30 min, with 15-20 min recovery intervals. Each total perfusion averaged $3 \mathrm{~h}$.

Reagents: D-glucose, D-glyceraldehyde, dihydroxyacetone, Dmannoheptulose, and L-arginine hydrochloride were purchased from Sigma Chemical Co., St. Louis, USA. The test substances were added to the basic perfusion medium by constant infusion syringes.

Analytical Methods: Somatostatin was measured by radioimmunoassay as previously described $[8,10,11]$, using the tyrosin ${ }^{11}$ analogue of somatostatin iodinated with ${ }^{125}$. The perfusion buffer was used as diluent for the standards. The detection limit was $2 \mathrm{pg} / \mathrm{ml}$. Insulin and glucagon were measured by specific sensitive radioimmunoassays as described previously [12]. A pancreatic glucagon specific anti-serum (Lise Heding, Novo Research Institute, Copenhagen) was used. Glucose was determined by a glucose-oxidase method [13] and urine tested for ketones by Ketostix.

Calculations: The percentage change in hormone secretion $(\triangle \%)$ was calculated from the mean of the one-minute hormone values during the entire carbohydrate infusion (B) and the mean of the last five one-minute values just prior to the addition of the carbohydrate (A) as $\Delta \%=\frac{\mathrm{B}-\mathrm{A}}{\mathrm{A}} \times 100 \%$.

Since the control values (A) for insulin were zero or almost zero the percentage changes were not calculated.

Statistical analyses were made by a two-tailed paired Student's 't'test with a $5 \%$ significance level.

\section{Results}

\section{Effect of Streptozotocin Treatment on Plasma Glucose, Insulin and Glucagon}

Streptozotocin produced a moderate to severe diabetic state with wasting, polyuria and moderate hyperglycaemia. The blood glucose level before streptozotocin treatment was $4.5 \pm 0.2 \mathrm{mmol} / \mathrm{l}$ (mean $\pm \mathrm{SEM}$, $n=11$, range $3.3-5.1 \mathrm{mmol} / \mathrm{l})$. On the day of operation, blood glucose levels had risen to $15.3 \pm$ $1.7 \mathrm{mmol} / 1$ (range $8.5-24.3 \mathrm{mmol} / \mathrm{l})(p<0.001)$. Plasma glucagon was also significantly elevated ( $p<$ 0.01 ) after streptozotocin administration; before: 36 $\pm 7 \mathrm{pg} / \mathrm{ml} \mathrm{(range} 10-70 \mathrm{pg} / \mathrm{ml}$ ); after: $548 \pm$ $147 \mathrm{pg} / \mathrm{ml}$ (range $100-1400 \mathrm{pg} / \mathrm{ml}$ ). Plasma insulin values were low and did not change significantly: before $2.4 \pm 0.8$ versus $1.4 \pm 0.6 \mathrm{mU} / 1$ after. All diabetic dogs had ketonuria.

\section{Somatostatin, Glucagon and Insulin Release from the Isolated Perfused Pancreas of Normal and Streptozotocin Diabetic Dogs in Response to $D$-Glyceraldehyde at Glucose 0 and $8.3 \mathrm{mmol} / \mathrm{l}$}

The effect of 10 min infusions of D-glyceraldehyde $5 \mathrm{mmol} / \mathrm{l}$ on somatostatin, glucagon, and insulin release from normal and diabetic preparations was studied in the absence of glucose. In the normal pancreas (Fig. 1, left panel) the triose elicited a clearcut, biphasic increase in somatostatin $(77 \pm 23 \%, p<$ 0.05 ) and insulin output while glucagon release was inhibited by $54 \pm 7 \%(p<0.001)$. After the removal of D-glyceraldehyde, control levels were reattained after a short-lived 'off' response. As seen in Figure 1 (right panel), insulin secretion by the diabetic pancreas was almost extinct throughout, while D-glyceraldehyde $5 \mathrm{mmol} / 1$ slightly suppressed somatostatin and glucagon secretion by $16 \pm 3 \%(p<0.05)$ and 20 $\pm 11 \%$ (NS), respectively.

At the high glucose concentration of $8.3 \mathrm{mmol} / \mathrm{l}$, release of insulin and somatostatin from the normal pancreas was relatively increased, whereas glucagon release was relatively low (Fig. 2, left panel). When D-glyceraldehyde $(5 \mathrm{mmol} / \mathrm{l})$ was added to the perfusate, $\mathrm{D}$ cell secretion was inhibited by $72 \pm 5 \%(p<$ $0.001)$, B cell secretion by $30 \pm 9 \%(p<0.05)$ and A cell secretion by $31 \pm 5 \%(p<0.05)$. In the same experiment in streptozotocin diabetic dogs (Fig. 2, right panel) D-glyceraldehyde ( $5 \mathrm{mmol} / \mathrm{l})$ did not alter the very low rate of insulin secretion, although it suppressed somatostatin secretion by $47 \pm 9 \%(p<$ $0.05)$ and glucagon secretion by $37 \pm 2 \%(p<0.001)$.

To see whether lower concentrations of D-glyceraldehyde also failed to stimulate $\mathrm{D}$ and $\mathrm{B}$ cell secretion in the diabetic state, the effect of D-glyceraldehyde 1.25 and $2.5 \mathrm{mmol} / \mathrm{l}$ was studied in the absence of glucose (Fig. 3). Neither somatostatin nor insulin secretion showed any significant change, while the higher concentration of D-glyceraldehyde $(2.5 \mathrm{mmol} / \mathrm{l})$ slightly reduced glucagon secretion (by $26 \pm 5 \%, p<0.01)$. After the perfusion of D-glyceraldehyde at $2.5 \mathrm{mmol} / 1$ there was a slight rebound in somatostatin and glucagon release. 

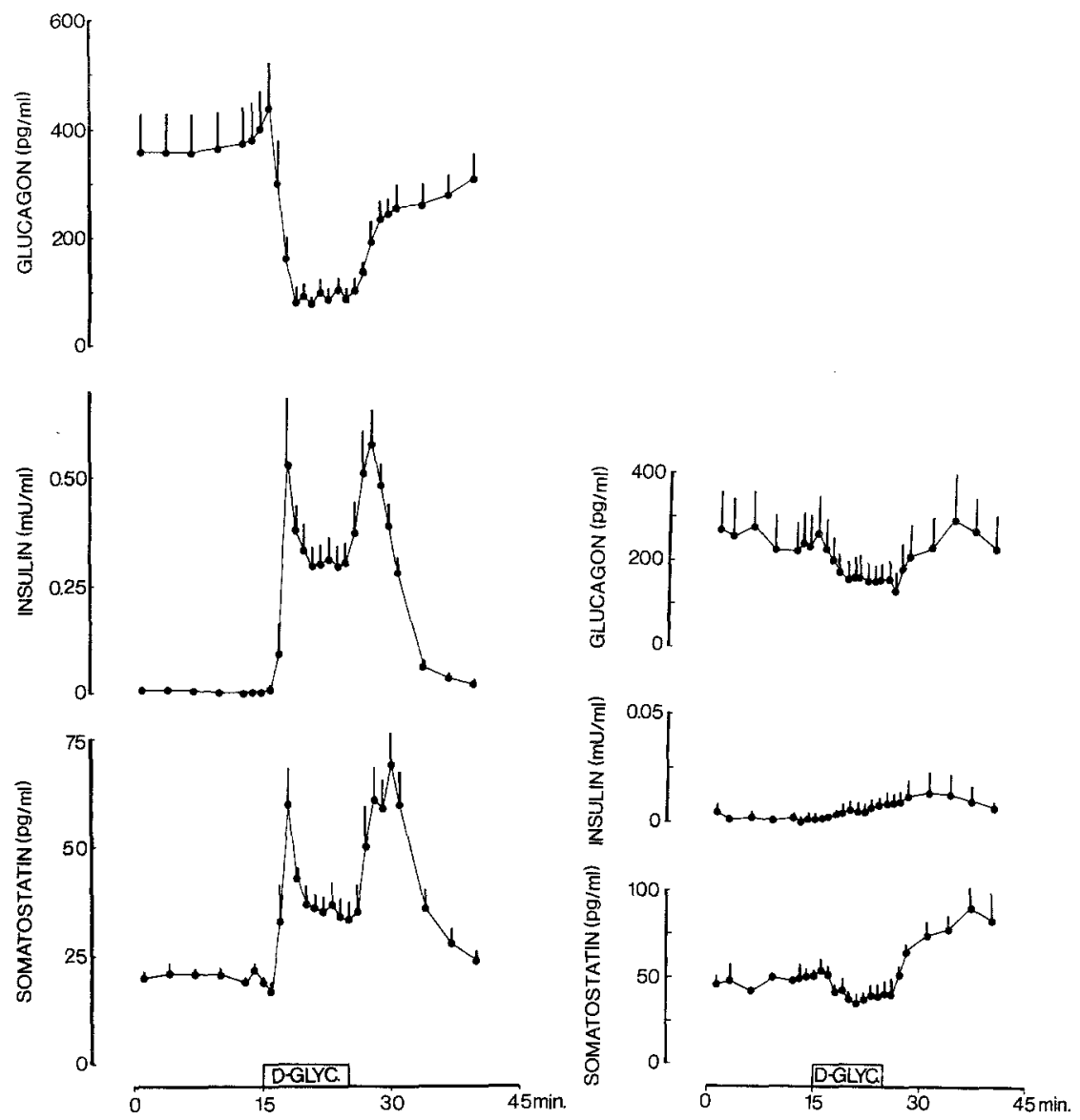

Fig. 1. Effect of D-glyceraldehyde (D-GLYC) $(5 \mathrm{mmol} / \mathrm{l})$ alone on glucagon, insulin and somatostatin release from the pancreas of normal (left panel, $n=6$ ) and streptozotocin diabetic dogs (right panel, $n=3$ ). Results are expressed as mean \pm SEM
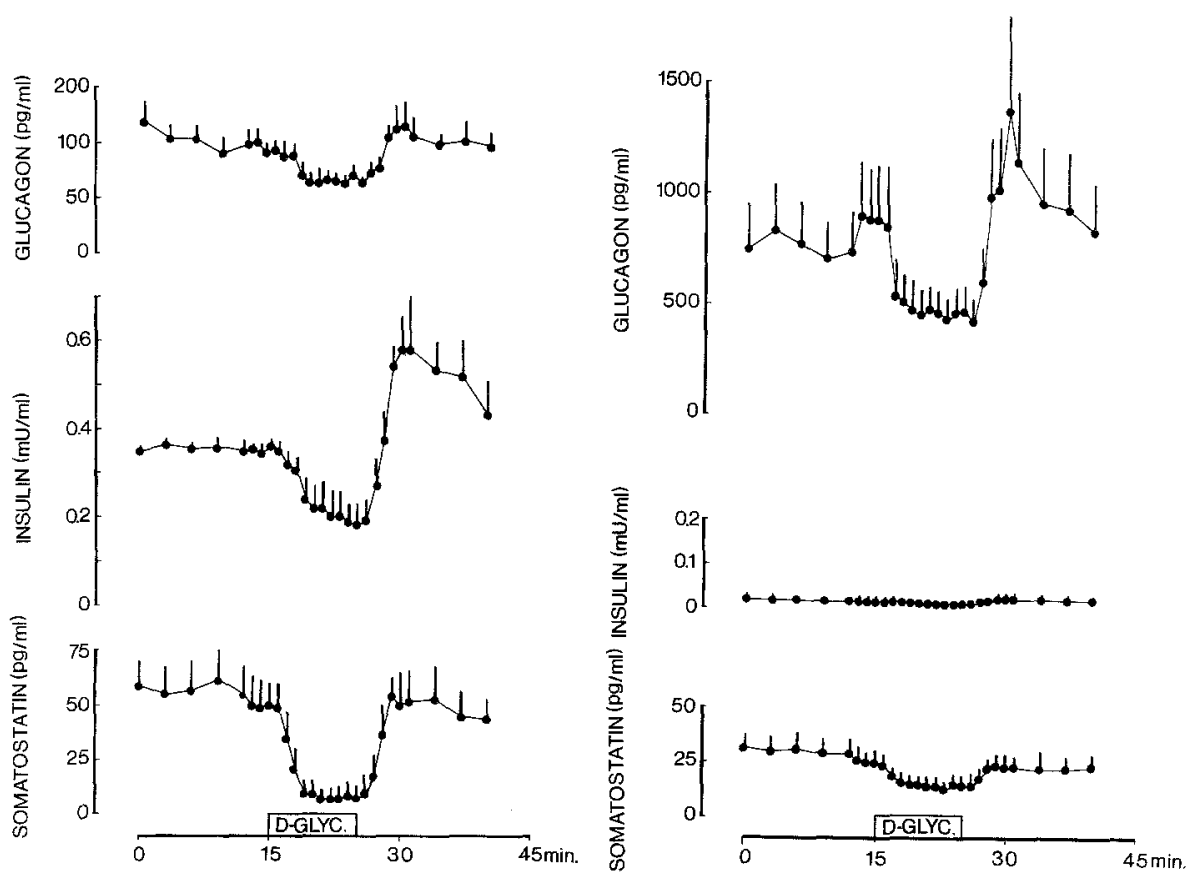

Fig. 2. Effect of D-glyceraldehyde (D-GLYC) $(5 \mathrm{mmol} / \mathrm{l})$ on glucagon, insulin, and somatostatin release from the pancreas of normal (left panel, $n=4$ ) and streptozotocin diabetic dogs (right panel, $n=4$ ) in the presence of glucose $(8.3 \mathrm{mmol} / \mathrm{l})$. Results are expressed as mean \pm SEM 


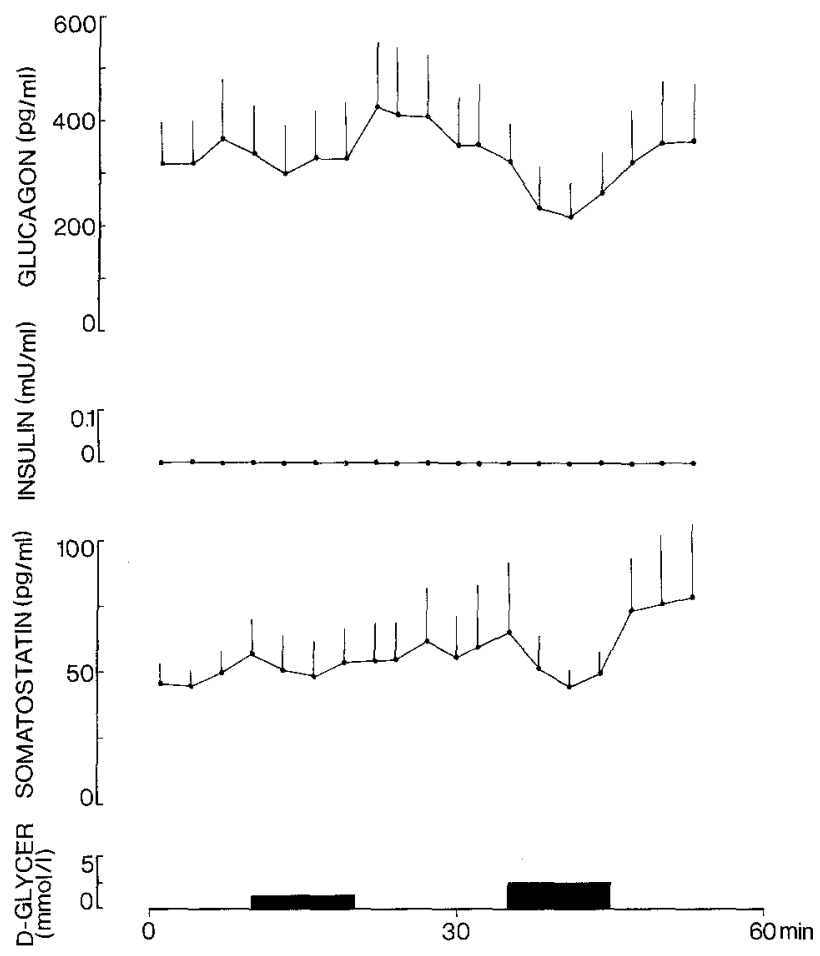

\section{Effect of Dihydroxyacetone in the Absence of Glucose}

The effect of 10 min perfusions of another triose, dihydroxyacetone, was investigated in three diabetic preparations. In the absence of glucose, the addition of dihydroxyacetone $(11 \mathrm{mmol} / 1)$ did not significantly alter the secretion of somatostatin or glucagon $(\Delta \%$ : $2 \pm 6 \%$ and $-7 \pm 8 \%$, respectively). B cell secretion was absent throughout the perfusions.

\section{Effect of Mannoheptulose at Glucose $8.3 \mathrm{mmol} / \mathrm{l}$}

In four diabetic preparations perfused with glucose at $8.3 \mathrm{mmol} / 1$, mannoheptulose $(5 \mathrm{mmol} / 1)$ was added for 10 min periods. Both somatostatin and glucagon release were unaffected by this metabolic blocking agent $(\Delta \%:-3 \pm 3 \%$ and $9 \pm 5 \%$, respectively).

Fig. 3. Effect of D-glyceraldehyde (1.25 and $2.5 \mathrm{mmol} / 1$ (D-GLYCER) on glucagon, insulin and somatostatin release from the pancreas of diabetic dogs $(n=3)$ in the absence of glucose. Results are expressed as mean $\pm \mathrm{SEM}$
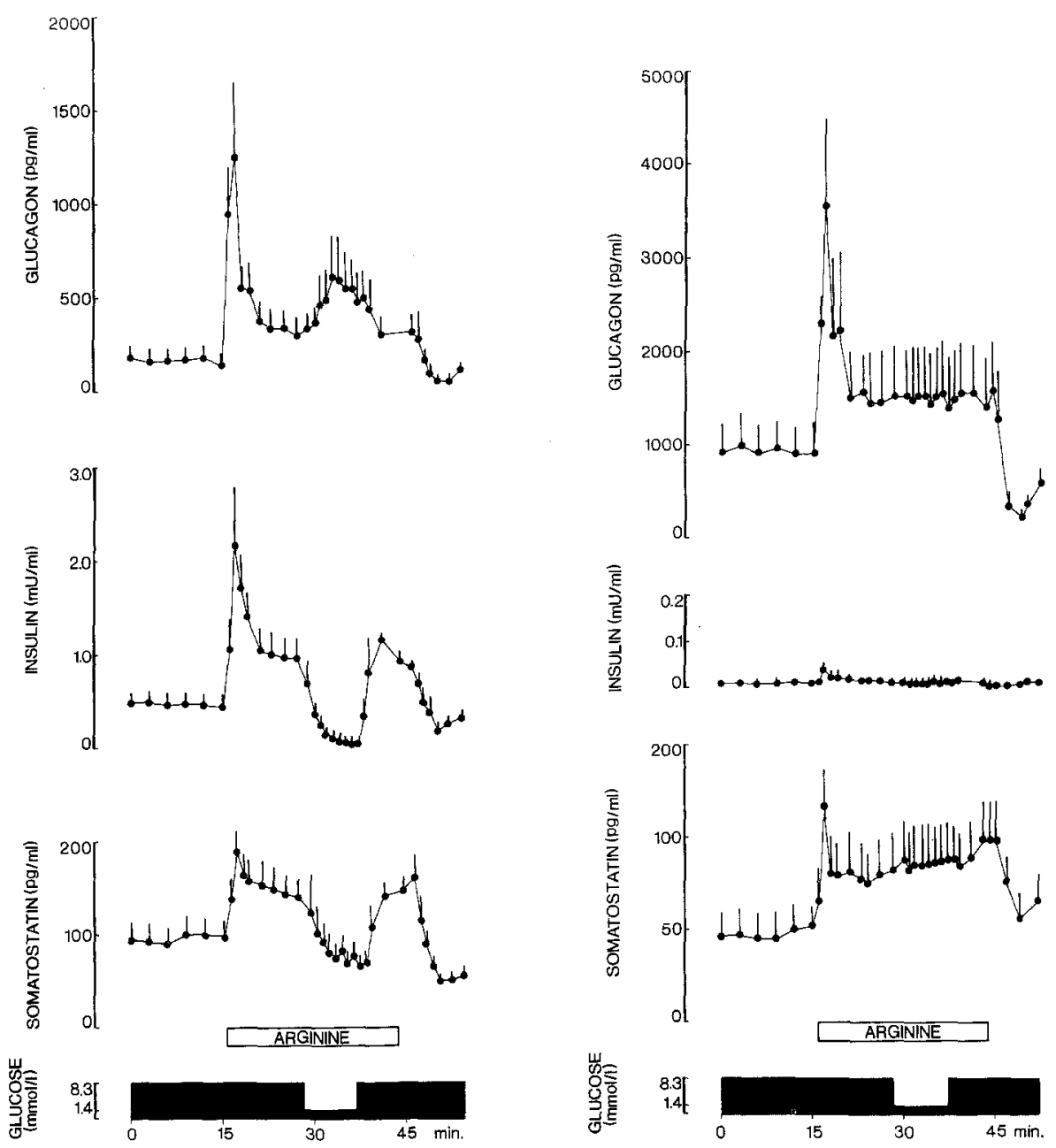

Fig. 4. Effect of arginine ( $5 \mathrm{mmol} / \mathrm{l})$ on glucagon, insulin and somatostatin release from the pancreas of normal (left panel, $n=4$ ) and streptozotocin diabetic dogs (right panel, $n=4$ ) during variation in the perfusing glucose concentration from 8.3 to $1.4 \mathrm{mmol} / 1$. Results are expressed as mean \pm SEM 


\section{Comparison of the Effect of Glucose Variation During Arginine Infusion in Normal and Diabetic Dogs}

The effect of varying the glucose concentration in the perfusate in the presence of arginine is shown in Figure 4 . In the normal pancreas arginine $(5 \mathrm{mmol} / \mathrm{l})$ clearly stimulated glucose $(8.3 \mathrm{mmol} / \mathrm{l})$ mediated somatostatin, glucagon and insulin secretion as expected (Fig. 4, left panel). A 10 min decrease in the glucose concentration of the perfusate to $1.4 \mathrm{mmol} / 1$ in the continued presence of arginine immediately blunted the secretion of somatostatin and insulin (by $37 \pm 5 \%, p<0.01$ and $71 \pm 4 \%, p<0.001$, respectively) while glucagon release was augmented by 46 $\pm 6 \%(p<0.01)$. With the restoration of the higher glucose level, hormone secretion attained its previous level.

In the diabetic pancreas arginine $(5 \mathrm{mmol} / \mathrm{l})$ also stimulated somatostatin and glucagon secretion (Fig. 4, right panel). However there was no decrement in somatostatin or increment in glucagon release in response to the lowering of the glucose concentration in the perfusate.

\section{Discussion}

Pancreatic $\mathrm{D}$ cell function is abnormal in experimental diabetes [1]. The rate of somatostatin release from the isolated pancreas of streptozotocin diabetic dogs is unaffected by variations in the level of glucose in the perfusate [1]. To explore the molecular basis of this D cell impairment, we have investigated somatostatin response in the pancreas of streptozotocin diabetic dogs to $\mathrm{D}$-glyceraldehyde, dihydroxyacetone and mannoheptulose, comparing them with that obtained in normal dogs.

It was found that concentrations of D-glyceraldehyde $(1.25$ and $2.5 \mathrm{mmol} / \mathrm{l})$ and dihydroxyacetone $(11 \mathrm{mmol} / \mathrm{l})$, which normally stimulate D cell secretion [8], did not do so in the perfused pancreas of streptozotocin diabetic dogs. We have already shown that D-glyceraldehyde at $5 \mathrm{mmol} / 1$ produces a maximal somatostatin response while $10 \mathrm{mmol} / 1$ produces a clear-cut inhibition [8]. The latter effect may be due to a non-specific action which reduces islet ATP concentration [14]. Knowing that glucose is degraded by the islets to D-glyceraldehyde phosphate [15], the suppressive effect observed in this study of D-glyceraldehyde $(5 \mathrm{mmol} / \mathrm{l})$ when infused with glucose $(8.3 \mathrm{mmol} / \mathrm{l})$ is not too surprising. In the diabetic preparations, D-glyceraldehyde $(5 \mathrm{mmol} / \mathrm{l})$ exerted a suppressive effect on D cell secretion, irrespective of the glucose concentration. Whether the above-mentioned non-specific effect contributes to the inhibito- ry action of D-glyceraldehyde on glucagon secretion in the streptozotocin diabetic pancreas is unknown.

In accordance with the previously demonstrated absent hormonal response to glucose in the diabetic pancreas [1], it was found that the metabolic blocking agent mannoheptulose $(5 \mathrm{mmol} / 1)$, which inhibits glucose metabolism and glucose mediated D and B cell secretion but which stimulates A cell secretion [2, 8] had no influence on islet cell secretion. In addition, arginine-stimulated pancreatic hormone secretion in the diabetic pancreas was unaffected by sudden changes in the glucose concentration of the perfusate.

A considerable body of evidence indicates that the metabolism of glucose within the D cell is fundamentally involved in the normal process of glucose recognition and the hormonal response it induces [8]. This concept is supported by the present findings which demonstrate that pancreatic $\mathrm{D}$ and A cell dysfunction in streptozotocin diabetes not only consists of impaired response to the intact glucose molecule but also involves a disorganization of the hormone response to glucose metabolites.

It remains unresolved whether the functional abnormalities of the $\mathrm{D}$ cell are caused by a direct action of streptozotocin, by a lack of endogenous insulin in the vicinity of the $\mathrm{D}$ cell or are secondary to abnormal intermediary metabolism.

In conclusion, pancreatic D cells in streptozotocin diabetes are characteristically unresponsive to glucose and glucose metabolites. This is probably due to a defect in their glucose recognition system.

Acknowledgements. Cyclic somatostatin for immunization and standards was kindly donated by Norman Grant, Wyeth Laboratories, Philadelphia, USA. Roger Guillemin, Salk Institute, La Jolla, California, generously gave me $\mathrm{Tyr}^{11}$-somatostatin for iodination. Karen Just and Eva Seier are thanked for expert technical assistance and Anette Larsen for typing the manuscript. This work was supported by grants from the Danish Medical Research Council, the University of Aarhus, the Novo Research Institute and the Nordic Insulin Foundation. A preliminary report of this work was presented at the 16th Annual Meeting of the European Association for the Study of Diabetes, September 24-27 (1980), Athens, Greece.

\section{References}

1. Hermansen K, Ørskov H, Christensen SE (1979) Streptozotocin diabetes: A glucoreceptor dysfunction affecting D cells as well as B and A cells. Diabetologia 17:385-389

2. Schauder P, McIntosh C, Arends G, Arnold R, Frerich H, Creutzfeldt W(1976) Somatostatin and insulin release from isolated rat pancreatic islets stimulated by glucose. FEBS Lett 68 : 225-227

3. Ipp E, Dobbs RE, Arimura A, Vale W, Harris V, Unger RH (1977) Release of immunoreactive somatostatin from the pancreas in response to glucose, amino acids, pancreozymin-cholecystokinin, and tolbutamide. J Clin Invest 60: 760-765 
4. Weir GC, Samols E, Day JA, Patel YC (1978) Glucose and glucagon stimulate the secretion of somatostatin from the perfused canine pancreas. Metabolism 27:1223-1226

5. Hermansen K, Christensen SE, Ørskov H, Lundbæk K (1978) Release of somatostatin in response to calcium, glucose, arginine, acetylcholine, and isoproterenol. Acta Endcrinol (Suppl) $88: 219$, A 36

6. Hara M, Patton G, Gerich J (1979) Increased somatostatin release from pancreases of alloxan diabetic rats perfused in vitro. Life Sci 24:625-628

7. Hermansen K (1980) Secretion of somatostatin from the normal and diabetic pancreas. Studies in vitro. Diabetologia 19: 492-504

8. Hermansen K (1981) Pancreatic D cell recognition of D-glucose, D-glyceraldehyde, dihydroxyacetone, D-mannoheptulose, D-fructose, D-galactose, and D-ribose. Diabetes 30: 203-210

9. Iversen J, Miles DW (1971) Evidence for a feed-back inhibition of insulin on insulin secretion in the isolated, perfused canine pancreas. Diabetes 20: $1-10$

10. Hermansen K, Christensen SE, Ørskov H (1979) Characterisation of somatostatin release from the pancreas. The role of calcium and acetylcholine. Diabetologia 16:261-266
11. Hermansen K (1980) The role of sodium in somatostatin secretion: evidence for the involvement of $\mathrm{Na}^{+}$channels in the release mechanisms. Endocrinology 106: 1843-1847

12. Ørskov H, Thomsen HG, Yde H (1968) Wick chromatography for rapid and reliable immunoassay of insulin, glucagon and growth hormone. Nature 219: 103-195

13. Christensen NJ (1967) Notes on the glucose oxidase method. Scand J Clin Lab Invest 19:379-384

14. Ashcroft SJA, Chatra L, Weerasinghe C, Randle PJ (1973) Interrelationship of islet metabolism, adenosine triphosphate content and insulin release. Biochem J 132: 223-231

15. Zawalich WS (1979) Intermediary metabolism and insulin secretion from isolated rat islets of Langerhans. Diabetes 28: $252-260$.

Received: 3 February 1981

and in revised form: 28 July 1981

K. Hermansen

2nd University Clinic of Internal Medicine,

Kommunehospitalet,

DK-8000 Aarhus C, Denmark 